\title{
Peertechz
}

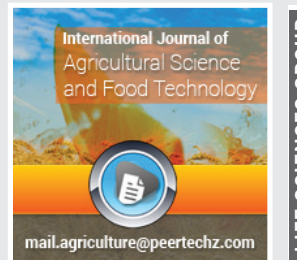

\section{How and what we eat impact our environment}

\author{
Rafael de Freitas Juliano and Jonathan Ballico de Moraes* \\ Department of Health Sciences and Biology, State University of Goiás, Itumbiara Unit, \\ Av. Modesto de Carvalho, S/Nº, Neighborhood, Agroindustrial District, CEP: 75536-100, \\ Itumbiara, Goiás, Brazil
}

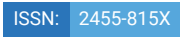

*Corresponding author: Jonathan Ballico de Moraes, Department of Health Sciences and Biology, State University of Goiás, Itumbiara Unit, Av. Modesto de Carvalho, $\mathrm{S} / \mathrm{N}^{\circ}$, Neighborhood, Agroindustrial District, CEP: 75536-100, Itumbiara, Goiás, Brazil, Tel: +5516981534401; E-mail: jonbmoraes@gmail.com

Keywords: Diet; Agriculture; Food; Health; Lifestyle; Nutrition Ecology

https://www.peertechzpublications.com

Check for updates

\section{Abstract}

Our dietary choices are one of the leading global causes of environmental degradation and decline in human health. The increasing consumption of fossil fuels, the emission of greenhouse gasses, deforestation and the extraction of fresh water by the food industry have triggered worldwide concern about the western lifestyle and our future in this world. Although modernization and new technologies in agriculture have helped end hunger, the lack of communication with environmental development promotes water and consequently food insecurity around the world, as well as malnutrition and an increase in chronic diseases. This mini-review summarizes the environmental and health impacts caused by the Western food industry and shows that we need to promote the development of food science together and in a communicative way with health and environmental sciences.

\section{Abbreviations}

\section{GHG: Greenhouse Gases}

\section{Introduction}

The food industry places a large and growing burden on the environment as well as on health. In fact, the Western diet depends on a mode of agricultural production that negatively impacts ecosystems, increases the use of fossil fuels and increases Greenhouse Gas (GHG) emissions and deforestation. In addition, due to the growth of the human population and the increase in per capita consumption, its impacts are expected to increase even more with the increase in future demand for agricultural products.

Unparalleled expansions of agricultural land since the 1700s, and technological innovations initiated in the 1930 s have allowed more caloric production per capita than has ever been available in human history. This remarkable success, however, came at a great cost. High agricultural technology represents $61 \%$ of GHG emissions from food, $79 \%$ from acidification and $95 \%$ from eutrophication [1]. The current agricultural system is also incredibly resource intensive, appropriating nearly half of the planet's fertile land. In addition, more than half of the use of freshwater is due to agribusiness, mainly in irrigation, which uses much more freshwater than industry, in addition to little contributions to the replacement of water in rivers and groundwater, causing water insecurity to medium and long term.

Modernization of the agricultural sector, justified on the grounds of "ending hunger", may have contributed to a significant proportion of the population having access to food, thus fulfilling a dimension of food and nutrition security However, the predominant production system does not dialogue with development and its conceptions of sustainability, further fostering food insecurity, since food production depends on the availability of fresh water and water security.

In recent decades, more and more communities are exposed to the Western lifestyle (associated with a high consumption of high-calorie foods, with an emphasis on animal and processed products) which has led to an increase in non-communicable chronic diseases linked to metabolic changes and chronic inflammatory state. The occurrence of these pathophysiological conditions together with the increase in population aging will likely drive the growing increase in non-communicable diseases across the globe.

During the $20^{\text {th }}$ century, many questions were raised about meat consumption and greenhouse gas emissions from 
food production and transportation. However, the direct link between human and ecosystem health was not always clear. Recent analyzes show an increase in demand for these foods, involved in high environmental impacts. In the period 19932013, for example, demand for animal products increased by $62 \%$, compared to a population increase of $29 \%$ [2]. This increase in consumption of animal-source foods is linked to an overall decline in health and increased metabolic and mortality risks.

Western societies have reached a tipping point where immune overactivation, due to the Western lifestyles, has reduced the healthy life expectancy of future generations. Epidemiological data reflect the simultaneous existence of malnutrition and overnutrition in several countries, referred to as the "double burden of malnutrition". The short-term consequences of this double burden include malnutrition related to premature child deaths, compromised immunity, physical development and cognitive skills. In the long term, it includes obesity, morbidities associated with chronic noncommunicable diseases and high mortality.

An example of this burden is Brazil, where the recent pattern of eating is also compatible with high levels of eating disorders and punctuates the epidemiological and nutritional scenario [3]. This correlates with a high risk of obesity and non-communicable chronic diseases, characterized by a high intake of added sugar and saturated fat. There is also a tendency to replace traditional meals based on fresh or minimally processed foods with ultra-processed foods. The consequence is the contamination of food and, subsequently, of water, air and soil, due to the use of various agricultural inputs and outputs. Various populations become vulnerable to these risks, not only those under the influence of monoculture landscapes, but also small communities of family farmers. There are still many barriers for the discussion of environmental impacts of food production and consumption to be considered in the agendas of Brazilian institutions in the area of Environmental, Nutrition and Public Health.

This nutritional transition had consequences: the accelerated climate change, associated with malnutrition and the fact that more than a third of the adult population is overweight, have brought us to the contemporaneity that Swinburn, et al. [2] called a "syndemic" lifestyle. This "syndemic" is expressed in the three most serious threats to human health and survival: the imbalance of climate, diet and body mass.

Indeed, there is currently a consensus that food choices link environmental sustainability and human health, leading us to conclude that sustainable diets can result in simultaneous reductions in environmental impacts and an boost human health. The current challenge is an arduous one: to reach a balance between the equitable advance of human health and, at the same time, sustaining the long-term health of the biosphere. A possible step forward in realizing this challenge may be collaboration between different scientific communities, especially those in health, nutrition and environmental science.
In this context, we can consider the perspective of Nutrition Ecology. This area comprises an interdisciplinary approach: in addition to describing and portraying interactions in the field of nutrition, it provides practical support for dealing with complex socio-environmental problems. Basically, there are four dimensions of Nutrition Ecology: health, environment, society and economy [4]. Providing a broad view of the entire food system, it covers subjects such as: total food quality, ecological balance, life cycle assessments, the influence of nutritional systems on the climate, population nutrition, food economy, comparison of different diets and agricultural, environmental and consumer policies.

From this perspective, we can consider the trilemma: environment-diet-health, which are strongly linked to a global challenge that manifests itself at different spatial scales, leading to a great opportunity to stimulate public health policies. Despite this relatively recent approach, two assumptions are predictable and can be widely tested from a nutritional-ecological point of view: (1) that an unbalanced diet and (2) higher consumption of animal products lead to greater environmental and health burdens. In fact, many studies have shown that the same dietary adjustments that might help reduce the risk of diet-related chronic diseases could also help achieve international sustainability goals, i.e., focusing our diets on foods that are consistently correlated with lower disease risk would also likely reduce diet-related environmental impacts [5]. Thus, the global priority of Nutrition Ecology is complex but pragmatic: to support dietary patterns that are environmentally sustainable (Especially in terms of greenhouse gas emissions), practical, cross-cultural, and to promote human health and well-being.

\section{Conclusion}

It is clear that strategical changes in the foods we choose would lead to better health and quality of life, reducing the global burden of noncommunicable chronic diseases. These changes towards more sustainable diets or dietary patterns that also have a lower environmental impact, meeting nutritional needs with health promotion, are those with a higher content of plant foods and fewer animal foods and reverberate in food and nutrition security. Implementation of available knowledge on the links between nutrition and health depends on the development of evidence-based guidelines and specific regional and national health targets.

\section{Acknowledgements}

The authors would like to thank the Universidade Estadual de Goiás

\section{References}

1. Poore J, Nemecek T (2018) Reducing food's environmental impacts through producers and consumers. Science 360: 987-992. Link: https://bit.ly/3wCOhwz

2. Swinburn BA, Kraak VI, Allender S, Atkins VJ, Baker PI, et al. (2019) The Global Syndemic of Obesity, Undernutrition, and Climate Change: The Lancet Commission report. Lancet 393: 791-846. Link: https://bit.ly/2U4TGNF 
3. Souza Ade M, Pereira RA, Yokoo EM, Levy RB, Sichieri R (2013) Most consumed foods in Brazil: National dietary survey 2008-2009. Revista de Saude Publica 47: 190-199. Link: https://bit.ly/3kfBLP4

4. Von Koerber K, Bader N, Leitzmann C (2017) Wholesome Nutrition: an example for a sustainable diet. Proceedings of the Nutrition Society 76: 34-41. Link: https://bit.ly/3kfBFqG
5. Clark MA, Springmann M, Hill J, Tilman D (2019) Multiple health and environmental impacts of foods. Proceedings of the National Academy of Sciences of the United States of America 116: 23357-23362. Link: https://bit.ly/2U7E7Vv

\section{Discover a bigger Impact and Visibility of your article publication with}

\section{Peertechz Publications}

\section{Highlights}

* Signatory publisher of ORCID

* Signatory Publisher of DORA (San Francisco Declaration on Research Assessment)

* Articles archived in worlds' renowned service providers such as Portico, CNKI, AGRIS, TDNet, Base (Bielefeld University Library), CrossRef, Scilit, J-Gate etc.

* Journals indexed in ICMJE, SHERPA/ROMEO, Google Scholar etc.

- OAI-PMH (Open Archives Initiative Protocol for Metadata Harvesting)

* Dedicated Editorial Board for every journa

* Accurate and rapid peer-review process

* Increased citations of published articles through promotions

* Reduced timeline for article publication

Submit your articles and experience a new surge in publication services (https://www.peertechz.com/submission).

Peertechz journals wishes everlasting success in your every endeavours.

Copyright: (c) 2021 De Freitas Juliano R, et al. This is an open-access article distributed under the terms of the Creative Commons Attribution License, which permits unrestricted use, distribution, and reproduction in any medium, provided the original author and source are credited. 